\title{
Hot spot pollutants: pharmaceuticals in the environment
}

\author{
Daniel R. Dietrich ${ }^{\mathrm{a}, *}$, Simon F. Webb ${ }^{\mathrm{b}}$, Thomas Petry ${ }^{\mathrm{c}}$ \\ a Environmental Toxicology, University of Konstanz, Konstanz, Germany \\ b Procter and Gamble, Bruxelles, Belgium \\ c The Weinberg Group, Bruxelles, Belgium
}

Pharmaceuticals are an important and indispensible element of modern life. They are employed in human and veterinary medicine, agriculture and aquaculture. Until the 1990s however, relatively little consideration was given to the likely fate, occurrence or effects of pharmaceuticals in the environment (PIE) following normal use. This apparent lack of scientific interest in pharmaceuticals as contaminants of the aquatic environment is somewhat puzzling. Common OTC drugs such as paracetamol or aspirin are sold in quantities comparable to high production volume (HPV) materials - close to or exceeding 1000 tons/annum in EU countries such as the UK or Germany (Webb, 2001; Ternes, 2001a). Total use of human prescription drugs in such countries will exceed this (Webb, 2001). Drugs are also inherently biologically active and often exquisitely potent. They are often resistant to biodegradation as metabolic stability is necessary to pharmacological action. Certain pharmaceuticals (or their metabolites) are also highly water soluble. When combined with a lack of biodegradation, removal during wastewater treatment will consequently be limited for such compounds. These compounds will consequently enter the aquatic environment to result in exposure of aquatic biota.

\footnotetext{
* Corresponding author.

E-mail address: daniel.dietrich@uni-konstanz.de (D.R. Dietrich).
}

Contributions to our knowledge of PIE that predate this period include the observations by Aherne et al. (1985) and others on compounds such as ethinyl oestradiol, diazepam, theophylline, erythromycin, tetracycline and methotrexate in various environmental matrices as a consequence of normal patient use. Richardson and Bowron (1985) likewise report on analytical studies. They also detail the development of simple modeling techniques aimed at predicting likely concentrations in surface waters following normal use by the patient. This pioneering work included a consideration of national usage patterns, human metabolism, fate during wastewater treatment and surface water dilution of effluents.

The last decade has seen a marked growth in the literature relating to observations of PIE at concentrations that result from normal use by the patient. At least 60 compounds have now been reported from aquatic matrices (Stumpf et al., 1996a,b; Heberer and Stan, 1997; Ternes, 1998; Hirsch et al., 1999; Ternes 2001a,b). Such observations necessitate a consideration of any potential risk. This in turn requires knowledge of the effects of pharmaceuticals upon relevant aquatic biota. This requirement is now being addressed for many classes of compounds such as SSRIs (Fong et al., 1998), steroids (Länge et al., 2001) and antihyperlipoproteinemics (Köpf, 1995). Concurrently, there have been various regulatory developments in the USA and the EU relating to 
requirements for risk assessment of new actives as part of their registration process. The risk assessment of existing pharmaceuticals has also been attempted (Halling-Sørenson et al., 1998; StuerLauridsen et al., 2000; Webb, 2001).

Of particular concern is speculation that the presence of PIE may be leading to subtle but hitherto unrecognized or undetected effects leading to irreversible damage of the ecosystem (Daughton and Ternes, 1999; Daughton, 2001). This requires empirical research aimed at thoroughly understanding the effects of these biologically active materials at the low exposure levels occurring in the environment (Pfluger and Dietrich, 2001). Equally important is the need to develop solid and scientifically sound approaches to assess the associated risks.

This special issue of Toxicology Letters contributes in our efforts to extend our knowledge vis-à-vis the occurrence and fate of PIE, their effects and potential risk. It represents a concerted effort of academic, regulatory and industry scientists to bring greater understanding to the PIE issue. Together these 13 papers reflect the stateof-the-art as presented at the Statuskolloqium in Konstanz, Germany (November 2001) and the Special Session at the SETAC Europe Annual Meeting in Vienna, Austria (May 2002).

In the section on 'Occurrence and Fate' the first three contributions from Heberer, Boxall and Straub all reflect analytical studies on the presence and fate of pharmaceutical residues in the environment. These include compounds such as antibiotics and UV-filters. The fourth paper from Schowanek and Webb details exposure modeling of common pharmaceuticals using the GREATER software.

Within the 'Effects' section, the three papers from Zerulla et al., Schmid and Köllner detail work on the responses of fish species to endocrine modulators (including steroids) and other compounds. Hutchinson presents work on the in vivo and in vitro responses of invertebrate species.

The first of the two contributions in the section entitled 'Principle Considerations' is by Länge and Dietrich who deal with various conceptual aspects of environmental risk assessment as it relates to pharmaceuticals. In the second, Seiler speculates on whether the established knowledge relating to the pharmacodynamic activity of pharmaceuticals can be of use in ecotoxicity.

Until recently pharmaceuticals were not subject to environmental risk assessment as part of the registration process. In the last section on 'Risk Assessment', there are three papers by Koschorrek, Montforts and Straub dealing with developments regarding EU regulatory requirements for the environmental risk assessment of new veterinary and human pharmaceutical actives.

Overall this Special Issue of Toxicology Letters aims at critically discussing the present knowledge on PIE, their potential impact on the environment and consequently the most proper and sensible steps for risk assessment. In combining the views from academic, industry and regulatory scientists the balanced presentation of the most pressing issues and gaps of knowledge is emphasized. This is especially important in view of the present efforts in regulating environmental testing and risk assessment within the EU. It is our express hope that this Special Issue of Toxicology Letters will foster discussion amongst scientists, stimulate additional efforts in addressing the knowledge gaps identified and thus provide for a better scientific basis of dealing with (PIE).

\section{Acknowledgements}

We would like to thank Karin Rieder for organizing this Special Topics Issue of Toxicology Letters and the various reviewers of the enclosed publications for doing such an excellent job in the little time that was available.

\section{References}

Aherne, G.W., English, J., Marks, V., 1985. The role of immunoassay in the analysis of microcontaminants in water samples. Ecotoxicol. Environ. Saf. 9 (1), 79-83.

Daughton, C.G., 2001. Illicit drugs in municipal sewage: proposed new non-intrusive tool to heighten public awareness of societal use of illicit/abused drugs and their potential for ecological consequences. In: Daughton, C.G., Jones-Lepp, T. (Eds.), Pharmaceuticals and Personal Care Products in the Environment: Scientific and Regulatory Issues. Sympo- 
sium Series 791, American Chemical Society, Washington DC, pp. 348-364.

Daughton, C.G., Ternes, T.A., 1999. Pharmaceuticals and personal care products in the environment: agents of subtle change? Environ. Health Perspect. 107 (6), 907-938.

Fong, P.P., Huminski, P.T., d'Urso, I.M., 1998. Induction of potentiation of parturition in fingernail clams (Sphaerium striatinum) by selective serotonin re-uptake inhibitors (SSRIs). J. Exp. Zool. 280 (3), 260-264.

Halling-Sørenson, B., Nors Nielsen, S., Lanzky, P.F., Ingerslev, F., Holten-Lutzhøft, H.C., Jørgenson, S.E., 1998. Occurrence, fate and effects of pharmaceutical substances in the environment - a review. Chemosphere 36 (2), $357-$ 393.

Heberer, T., Stan, H.-J., 1997. Determination of clofibric acid and $N$-(phenylsulfonyl)-sarcosine in sewage river and drinking water. Int. J. Environ. Anal. Chem. 67, 113-124.

Hirsch, R., Ternes, T., Haberer, K., Kratz, K.-L., 1999. Occurrence of antibiotics in the aquatic environment. Sci. Total Environ. 225, 109-118.

Köpf, W., 1995. Wirkung endokriner Stoffe in Biotests mit Wasserorganismen. Vortag bei der 50. Fachtagung des Bayerisches Landesamt für Wasserwirtschaft: Stoffe mit endokriner Wirkung im Wasser (Abstract). [Effects of endocrine substances in bioassays with aquatic organisms. Presentation at the 50th Seminar of the Bavarian Association for Waters Supply. Substances with endocrine effects in water (Abstract).] Quoted in Römbke et al. (1995).

Länge, R., Hutchinson, T.H., Croudace, C.P., Siegmund, F., Schweinfurth, H., Hampe, P., Panter, G.H., Sumpter, J.P., 2001. Effects of the synthetic oestrogen 17a-Ethinylestradiol over the life-cycle of the fathead minnow (Pimephales promelas). Environ. Toxicol. Chem. 20 (6), 1216-1227.

Pfluger, P., Dietrich, D.R., 2001. Pharmaceuticals in the environment-an overview and principle considerations. In: Kümmerer, K. (Ed.), Pharmaceuticals in the Environment.
Springer-Verlag, Heidelberg Chapter 2: 11-17, ISBN 3540-41067-8.

Richardson, M.L., Bowron, J.M., 1985. The fate of pharmaceutical chemicals in the environment. J. Pharm. Pharmacol. 37, 1-12.

Stuer-Lauridsen, F., Birkved, M., Hansen, L.P., HoltenLutzhøft, H.C., Halling-Sørenson, B., 2000. Environmental risk assessment of human pharmaceuticals in Denmark after normal therapeutic use. Chemosphere 40 (7), 783793.

Stumpf, M., Ternes, T.A., Haberer, K., Baumann, W., 1996a. Nachweis von natürlichen und synthetischen Östrogenen in Kläranlagen und Fliessgewässern. Vom Wasser 87, 251261.

Stumpf, M., Ternes, T.A., Haberer, K., Seel, P., Baumann, W., 1996b. Nachweis von Arzneimittelrückständen in Kläranlagen und Fließgewässern. Vom Wasser 86, 291 303.

Ternes, T.A., 1998. Occurrence of drugs in German sewage treatment plants and rivers. Water Res. 32 (11), 32453260 .

Ternes T., 2001a. Pharmaceuticals and metabolites as contaminants of the aquatic environment. In: Daughton, C.G., Jones-Lepp, T.L. (Eds.), Pharmaceuticals and Personal Care Products in the Environment - Scientific and Regulatory Issues. ACS Symposium Series 791, American Chemical Society, Washington DC, USA, pp. 39-54.

Ternes, T.A., 2001b. Analytical methods for the determination of pharmaceuticals in aqueous environmental samples. Trends Anal. Chem. 20 (8), 419-434.

Webb, S.F., 2001. A data based perspective on the environmental risk assessment of human pharmaceuticals IIaquatic risk characterization. In: Kümmerer, K. (Ed.), Pharmaceuticals in the Environment-Sources, Fate, Effects and Risks. Springer-Verlag, Berlin, Heidelberg, Germany, pp. 203-219. 